\title{
UNGKAPAN BERMAKNA BUDAYA DALAM UPACARA ADAT PERNIKAHAN MASYARAKAT ETNIK GORONTALO THE EXPRESSIONS USED AND EXPRESSED IN A TRADITIONAL WEDDING CEREMONY ON THE GORONTALO'S ETHNIC
}

\author{
Mercy Mantau \\ Fakultas Ilmu Budaya Unsrat Manado \\ Jalan Kampus Unsrat Bahu, Manado, Sulawesi Utara \\ mercymantau2011@gmail.com
}

\begin{abstract}
This research aims to describe and analyze the expressions used and expressed in a traditional wedding ceremony especially during the Motolobalango (to the marriage proposed), Modutu (to bring dowry delivery), and Moponika (to marry the couple) phases based on the Gorontalo's cultural context, in obtaining their meanings, and to discover their patterns of thinking through the cultural meaning expressions.

The data have been gathered throuch participation observations and interviews. The model of interviewing used, have been taken from Spradley (1979) which are descriptive questions consisting of grand tour questions, mini tour questions, example questions, and experience questions. After that, the data were described by using ethnography of SPEAKING technic by Dell Hymes. The three important phases of traditional wedding ceremony contain eight aspects of SPEAKING acronym.

The research result shows that there are a lot of cultural meaning expressions in the Gorontalo culture. The results of this study are presented as follows: the communication processes are being caried out by verbal and nonverbalperformances and can describe the Gorontalo people's patterns of thinking which are among other: religious, handworking, showing, and appreciating good manner in their social and family lives.
\end{abstract}

Keywords: expressions, Gorontalo Language, SPEAKING

\begin{abstract}
Abstrak
Penelitian ini bertujuan untuk mendeskripsikan ungkapan-ungkapan dalam upacara adat pernikahan etnik Gorontalo, terutama yang terdapat dalam tiga tahap terpenting dalam upacara adat tersebut, yaitu motolobalango, modutu, dan moponika; menganalisis ungkapan-ungkapan tersebut berdasarkan konteks budaya Gorontalo untuk memperoleh makna budayanya, dan menjelaskan pola pikir masyarakat etnik Gorontalo berdasarkan makna budaya ungkapan-ungkapan tersebut.

Data dikumpulkan dengan menggunakan metode observasi partisipasi yang dilengkapi dengan teknik wawancara yang dikemukakan oleh Spradley (1979). Selanjutnya, data dijabarkan dengan menggunakan teknik Ethnography of Speaking yang dikemukakan oleh Dell Hymes (1974). Ketiga tahap terpenting mengandung delapan aspek akronim SPEAKING tersebut. Hasil penelitian menunjukkan bahwa dalam tahapan upacara adat pernikahan etnik Gorontalo, khususnya dalam tahap motolobalango (meminang), modutu (mengantar harta pernikahan), dan moponika (menikahkan) terdapat ungkapanungkapan yang mengandung makna budaya yang dilantunkan dalam bentuk puisi tradisional yang disebut tuja'i dan palebohu.

Berdasarkan hasil penelitian dapat disimpulkan bahwa proses komunikasi dalam ketiga tahapan tersebut berlangsung lancar, baik secara verbal maupun nonverbal, juga menggambarkan pola pikir masyarakat etnik Gorontalo yang religius, pekerja keras, mengagungkan nilai tatakrama dalam pergaulan, dan kekeluargaan.
\end{abstract}

Kata kunci: Ungkapan-ungkapan, Bahasa Gorontalo, SPEAKING 


\section{Pendahuluan}

Sebagai bangsa berbudaya, masyarakat Indonesia yang terdiri dari beragam suku bangsa memiliki beragam bahasa daerah yang digunakan dalam proses komunikasi sehari-hari. Bahasa daerah ini telah diwariskan secara turuntemurun dan menjadi lambang identitas diri dari suatu komunitas budaya. Berhubungan dengan hal tersebut, masyarakat etnik Gorontalo pun memiliki tiga bahasa daerah yang digunakan sebagai media komunikasi dan diwariskan dari satu generasi ke generasi berikutnya, yaitu bahasa Gorontalo, bahasa Suwawa, dan bahasa Atinggola. Dari ketiga bahasa tersebut, bahasa Gorontalo paling banyak penuturnya, tersebar dari wilayah Kota Gorontalo, Kabupaten Gorontalo, sebagian wilayah Kabupaten Gorontalo Utara hingga Kabupaten Pohuwato. Sementara itu, bahasa Atinggola hanya digunakan oleh penduduk yang bermukim di wilayah Kecamatan Atinggola, Kabupaten Gorontalo Utara. Demikian pula halnya dengan bahasa Suwawa hanya digunakan oleh sebagian penutur yang bermukim di wilayah Kecamatan Suwawa, Kabupaten Bone Bolango.

Bahasa dan budaya bagaikan dua sisi dari satu mata uang yang tak terpisahkan sebab kandungan nilai dalam setiap budaya dapat terungkap melalui penggunaaan bahasa dalam kehidupan manusia sehari-hari. Kehidupan manusia pada hampir semua lapisan masyarakat di dunia ini terbagi dalam tingkatan-tingkatan tertentu. Tingkatan kehidupan individu dalam antropologi disebut life-cycle, contoh: masa bayi, masa kanak-kanak, masa remaja, masa sesudah pernikahan, dan masa tua. Pada masa peralihan ketika individu beralih dari satu tingkat kehidupan ke tingkat kehidupan lain, biasanya diadakan pesta atau upacara adat untuk merayakan masa peralihan tersebut. Upacara ini bersifat universal karena hampir semua komunitas masyarakat di dunia ini memilikinya. Sifat universal ini disebabkan oleh adanya pemahaman umum pada manusia bahwa setiap tingkat kehidupan akan membawa seseorang ke dalam lingkungan sosial yang baru dan lebih luas. Hanya saja tidak semua masa peralihan dianggap sama pentingnya dalam semua budaya. Satu masa peralihan yang terpenting dalam siklus kehidupan manusia adalah masa peralihan dari tingkat kehidupan remaja ke tingkat kehidupan berkeluarga, yaitu pernikahan. Pernikahan merupakan bagian kehidupan manusia yang amat suci dan akan membawa kebahagiaan serta meninggalkan kesan yang menyenangkan dan mengagumkan apabila prosesi pernikahan dilaksanakan menurut upacara adat yang sesuai dengan tahapan pernikahan (Koentjaraningrat 1985:88-90).

Adat-istiadat merupakan norma yang sangat dijunjung tinggi oleh individu atau masyarakat yang menganutnya dan menanamkan kepercayaan yang teguh akan kemahakuasaan Allah SW'T yang mencipta manusia dengan kesempurnaan. Selain itu, adat-istiadat menjadi wujud kebudayaan yang berisi nilai-nilai luhur yang berfungsi juga sebagai tata krama yang mengatur, mengendalikan, dan memberi arah kepada perilaku setiap individu dalam bermasyarakat. Atas dasar itulah maka adatistiadatGorontalosebagaibagiandarikebudayaan nasional perlu dibina dan dilestarikan untuk menunjang dan membantu terwujudnya tujuan nasional yang tercantum dalam pasal 32 UUD 45 tentang pembinaan dan pengembangan kebudayaan nasional maupun daerah (Usman, 2008:140). Daerah Gorontalo sebagai salah satu dari 19 wilayah adat di Indonesia memiliki 
kebudayaan yang dipengaruhi ajaran agama Islam dalam mengatur aktivitas kehidupan masyarakat Gorontalo sehingga dapat memberi keseimbangan hidup dalam penyelenggaraan pemerintahan, keagamaan, ekonomi dan sosial kemasyarakatan. Perpaduan adat dan syariat Islam sebagaimana terungkap dalam tahuda (pesan kearifan) yang ditinggalkan oleh Sultan Eyato, yaitu adati bula-bula'o to sareati, sareati bula-bula'o to kitabullab 'adat bersendikan syarak, syarak bersendikan kitabulah". Pesan moral ini telah terpatri dalam ritme kehidupan sehari-hari masyarakat Gorontalo (Botutihe, 2003:16).

Eratnya hubungan adat istiadat etnik Gorontalo dengan agama Islam didasarkan pada fakta sejarah yang menyebutkan bahwa agama Islam telah masuk ke Gorontalo sejak abad XVI (tahun 1525) pada masa pemerintahan Raja Amay. Sistem peradatan yang telah turun temurun dari dahulu hingga sekarang masih tetap diberlakukan sesuai dengan ungkapan adat malo kakali, lonto butu asali, tobuliya waliwali 'sudah tetap dari awal mula dan sampai kini masih tetap berlaku'. Berkaitan dengan adat istiadat Gorontalo yang bernuansa Islam, salah satu contoh, yakni pernikahan adat Gorontalo. Proses pelaksanaan upacara adat pernikahan Gorontalo meliputi beberapa tahap, yaitu mongilalo 'meninjau', mohabari 'meminta penjelasan', modulohupa 'musyawarah informal', baalanga 'penyampaian hari peminangan', motolobalango 'meminang', modutu 'mengantar harta pernikahan' (mencakup tahap modepita maharu 'mengantar mahar' dan modepita dilonggato 'mengantar bahan makanan'), moponika 'menikahkan' (mencakup tahap mohatamu Qur'ani 'khatam Alquran', mopotilandabu 'mempertunangkan', mongakaji 'akad nikah', momalebohu 'menasihati dan mendoakan', dan modelo 'membawa pengantin ke rumah orang tua pengantin pria' (Botutihe, 2003:15).

Pada tahap-tahap prosesi adat pernikahan etnik Gorontalo biasanya digunakan ungkapanungkapan bahasa yang indah yang disampaikan dengan cara dilantunkan dalam bentuk Tuja'idan Palebohu oleh para baate (ketua pemangku adat), baik dari keluarga laki-laki maupun keluarga perempuan. Tuja'i dan palebohu yang merupakan dua bentuk sastra lisan Gorontalo merupakan bentuk ungkapan bahasa lisan yang dipuisikan dengan sangat menarik dan diubah sedemikian rupa sehingga maksud, gagasan, semangat, serta keyakinan yang terkandung di dalamnya, misalnya, yang disampaikan pihak laki-laki pada saat tolobalango (peminangan) dapat diterima dengan baik oleh pihak keluarga perempuan (Lihawa, 2008:171). Pada masa sekarang ini masyarakat Gorontalo pada umumnya tidak hanya menggunakan bahasa Gorontalo dalam berkomunikasi karena mereka pada umumnya sudah menggunakan bahasa Indonesia, misalnya, dalam situasi resmi, seperti urusan administrasi, pemerintahan, atau menggunakan bahasa Melayu Manado dalam pergaulan seharihari. Sementara itu, dalam prosesi adat, seperti pernikahan, kelahiran anak, kematian, dan penganugerahan gelar adat, bahasa Gorontalo sebenarnya sejak dahulu kala sudah memegang peran penting karena menjadi bahasa pengantar utama dalam berkomunikasi. Keunikan bahasanya tampak pada penggunaan ungkapanungkapan bahasa yang dituja’i (dipuisikan) yang tidak saja terdengar indah ketika dituturkan, tetapi sarat pula dengan nilai-nilai moral.

Pada zaman dahulu makna ungkapanungkapan bahasa yang dituturkan oleh para pemangku adat dalam suatu upacara adat masih dipahami oleh orang Gorontalo pada 
umumnya. Namun, pada masa sekarang ini ungkapan-ungkapan tersebut kurang dipahami lagi, terutama oleh para generasi mudanya. Hal ini tidak terlepas dari adanya perubahan bentuk pemahaman dan pola berpikir orang Gorontalo yang sudah tersentuh pula oleh arus modernisasi sehingga mempengaruhi karakter orang Gorontalo dalam memandang dan memperlakukan budaya-budaya lokal etnik Gorontalo. Mereka menguasai bahasa Gorontalo dengan baik, tetapi mereka tidak memahami lagi makna yang terkandung dalam sastra lisan, seperti Tujai dan Palebohu. Padahal, apabila diteliti lebih mendalam, di dalam kedua bentuk sastra lisan ini banyak terdapat ungkapan yang maknanya mencerminkan konsep pola pikir masyarakat etnik Gorontalo yang sesungguhnya.

Penelitian tentang bahasa dan budaya etnik Gorontalo selama ini telah banyak dilakukan oleh peneliti-peneliti, baik dari dalam negeri maupun luar negeri, seperti bahasawan Wilhelm Joest (1883), Breukink (1906), Mansoer Pateda (1977), dan Yus Badudu (1982). Penelitian ini mengkaji relasi bahasa dengan budaya etnik tertentu. Dengan demikian, kerangka teori yang digunakan dalam penelitian ini adalah kerangka teori Linguistik Antropologi. Menurut Folley (1997), Linguistik Antropologi merupakan cabang linguistik yang menempatkan bahasa dalam konteks sosial budaya. Dalam hal ini peneliti dapat melihat bagaimana bahasa dipakai dalam struktur sosial yang dikaitkan dengan konteks budayanya. Linguistik Antropologi memandang bahasa melalui konsep inti Antropologi, yaitu budaya dan mencari makna yang terkandung di balik ungkapan-ungkapan bahasa tersebut. Dalam teori ini, bahasa dikaji dalam kaitannya dengan sikap dan perilaku budaya etnik tertentu, yaitu etnik Gorontalo, terutama mengenai interaksi sosial budaya masyarakat etnik tersebut. Dasar pemakaian kajian ini bertolak dari hipotesis SapirWhorf yang berasumsi bahwa cara pandang seseorang terhadap realitas dipengaruhi oleh bahasanya atau dengan kata lain bahasa mempengaruhi pola pikir manusia. Bahasa yang digunakan merefleksikan budaya penuturnya (Wardhaugh,1986:212). Hal ini diperkuat oleh pernyataan pakar Sosiolinguistik, Hudson yang menjelaskan bahwa bahasa tercakup dalam budaya. Oleh karena itu, tuturan dalam komunikasi verbal sering menceminkan nilainilai budaya yang dianut oleh penutur suatu bahasa, baik secara langsung maupun tidak langsung. Dengan demikian, bahasa menjadi cermin budaya suatu komunitas masyarakat (Kadarisman, 2005:152).

Bahasa memainkan peran yang sangat penting dalam sendi-sendi kehidupan manusia karena tanpa bahasa manusia akan mengalami kesulitan dalam proses berinteraksi dengan sesama, contohnya dalam suatu upacara adat pernikahan. Konsep pernikahan itu sendiri adalah suatu titik kulminasi janji setia dua anak manusia yang dilandasi rasa tanggung jawab, saling menghormati demi keutuhan dan kebahagiaan rumah tangga. Suatu pernikahan akan langgeng jika selalu berpegang pada normanorma agama dan norma adat yang berlaku dalam masyarakat. Selain itu, pernikahan akan membawa kebahagiaan serta meninggalkan kesan yang mengagumkan jika dilaksanakan menurut upacara adat yang sesuai dengan tahapan pernikahan (lenggotalonika). Dalam suatu peristiwa adat, seperti upacara adat pernikahan, proses komunikasi berlangsung, baik secara verbal maupun nonverbal. Komunikasi secara 
verbal tampak dalam ungkapan-ungkapan bahasa yang digunakan dalam upacara adat tersebut, sementara komunikasi nonverval akan tampak melalui perilaku partisipan dan penggunaan atribut-atribut adat.

Menurut Kridalaksana(1984), ungkapan adalah konstruksi satuan bahasa yang maknanya melebihi dari makna leksikal dan bahkan makna gramatikal yang terkandung dalam bahasa tersebut. Marnita dan Oktavianus (2008:220) mengemukakan bahwa ungkapan merupakan sarana yang dapat mempertajam intelektual karena ungkapan menggunakan kata-kata kias yang maknanya tidak langsung dan hanya bisa dimengerti dengan cara memahami alam dan budaya lokal. Makna suatu ungkapan bahasa merupakan sesuatu yang dapat mewakili pola pikir suatu masyarakat. Selanjutnya, ungkapan bahasa yang sudah dikaitkan dengan suatu budaya akan mencerminkan makna budaya yang pada akhirnya dari makna budaya tersebut dapat diperoleh cerminan pola pikir suatu komunitas masyarakat.

Senada dengan hal tersebut, Casson (1981:18) menegaskan bahwa budaya adalah pola pikir yang merupakan sistem kognisi yang keluar lewat bahasa dalam bentuk lisan maupun tulis. Sementara itu, Chomsky yang disitir oleh Kadarisman (2005:152) berpendapat bahwa bahasa merupakan cermin pikiran manusia ( $a$ mirror of mind) yang berarti terdapat hubungan antara kegiatan berpikir dan komunikasi yang berkaitan erat dengan perilaku penutur bahasa tersebut. Dengan demikian, dapatlah dikatakan bahwa kehidupan manusia tidak dapat dipisahkan dari bahasa. Bahasa dapat mengekspresikan realitas budaya yang pada akhirnya dijadikan pedoman bagi setiap individu dalam kehidupan bermasyarakat. Ungkapan bahasa menjadi media untuk menampilkan pola pikir masyarakat yang tercermin melalui makna budaya.

Preferensi penggunaan bahasa selain bahasa Gorontalo turut mempengaruhi tingkat pengetahuan tentang ungkapan bahasa Gorontalo. Di satu pihak, penggunaan bahasa Indonesia merupakan suatu pertanda baik bagi keberadaan bahasa Indonesia sebagai bahasa nasional, tetapi di pihak lain intervensi bahasa Indonesia dalam ranah peradatan Gorontalo menjadi pertanda buruk bagi pelestarian bahasa Gorontalo sebagai satu identitas diri orang Gorontalo. Hal inilah yang mendorong penulis untuk melakukan penelitian tentang adat-istiadat etnik Gorontalo, khususnya mengkaji aspek bahasa dalam upacara adat pernikahan etnik Gorontalo. Dalam hal ini, penulis membatasi uraian pada ungkapan bahasa yang terdapat dalam tiga tahap terpenting pada upacara adat pernikahan Gorontalo, yaitu tahap motolobalango 'meminang', tahap modutu 'mengantar harta pernikahan' yang terdiri dari upacara adat modepita maharu 'mengantar mahar' dan modepita dilonggato 'mengantar bahan makanan', dan tahap moponika 'menikahkan'. Salah satu contoh ungkapan bahasa yang terdapat dalam tahap motolobalango: paramata to buali unti-unti to lamari permata dalam kamar terkunci di dalam lemari'. Makna budaya yang tersirat dalam ungkapan ini adalah gadis cantik yang masih terjaga kehormatannya dan dijaga ketat oleh keluarganya.

Topik ini menarik perhatian penulis karena kajian ini memadukan antara aspek bahasa dan budaya. Makna budaya dalam upacara adat pernikahan etnik Gorontalo tidak hanya tergambar dari ungkapan bahasa yang digunakan, melainkan juga dalam penggunaan 
atribut-atribut budaya, antara lain tonggu, tapabula, sirih, pinang, dan bahan-bahan lain yang dibawa ketika tahap tolobalango 'peminangan' hingga puncak acara pelaksanaan pernikahan tersebut. Selanjutnya, berdasarkan makna-makna budaya tersebut dapat terungkap bagaimana pola pikir masyarakat etnik Gorontalo memandang realitas kehidupannya. Yang menjadi tujuan penelitian ini adalah sebagai berikut. 1) mendeskripsi ungkapan-ungkapan yang berkaitan dengan tahapan upacara adat motolobalango, modutu, dan moponika. 2) menganalisis ungkapan-ungkapan berdasarkan konteks budaya Gorontalo untuk memperoleh makna budayanya, dan 3) menjelaskan pola pikir masyarakat etnik Gorontalo berdasarkan makna budaya ungkapan.

\section{Metodologi}

Penelitian dilaksanakan di Provinsi Gorontalo, khususnya di Wilayah Limboto, Kabupaten Gorontalo. Pemilihan lokasi ini didasarkan pada pertimbangan bahwa Limboto merupakan salah satu pusat kebudayaan etnik Gorontalo. Dahulu kala Kerajaan Limboto (Pohala"a Limboto) merupakan satu dari lima kerajaan di Gorontalo yang saling bekerja sama dengan membentuk satu ikatan persaudaraan yang disebut Limo lo Pohala'a yang terdiri dari Pobala'a Hulonthalo, pohala'a limutu, pobala'a Suwawa, pohala'a Bolango, dan pohala'a Atinggola. Pohala'a bulonthalo dan pobala'a limutu yang disebut juga duluo limo lo pohala" a merupakan dua pohala'a yang terbesar di jazirah Gorontalo. Kedua pohala'a tersebut menggunakan bahasa Gorontalo sebagai media interaksi utamanya. Bahasa Gorontalo masih digunakan secara aktif dalam aktivitas komunikasi, khususnya dalam upacara adat, misalnya upacara adat pernikahan. Seperti diketahui bahwa di Provinsi
Gorontalo terdapat tiga bahasa besar, yaitu bahasa Gorontalo, bahasa Suwawa, dan bahasa Atinggola.

Penulis menggunakan tiga informan utama dan tujuh informan pendamping, merupakan penutur asli yang menguasai secara mendalam bahasa dan budaya Gorontalo.

\section{Pembahasan}

Dalam pelaksanaan tahap-tahap upacara adat pernikahan etnik Gorontalo, terutama dalam tiga tahap utama, yaitu motolobalango, modutu, dan moponika terdapat banyak mungkapan bahasa yang indah dalam bentuk peribahasa ataupun perumpamaan yang dipuisikan (tuja' i) oleh pemangku adat (baate).

Konsep Hymes (1974) yang diakronimkan dengan SPEAKING menjadi media penjabaran peristiwa tutur yang terjalin dalam prosesi adat motolobalango, modutu, moponika. Konsep ini meliputi $S$ (setting and scene) yang mengacu pada latar tempat dan waktu pelaksanaan, termasuk pula situasi tuturan ketika peristiwa tutur berlangsung; $P$ (paticipants andprop) yang mengacu pada peserta dan atribut yang digunakan; $E$ (ends) yang mengacu pada tujuan yang ingin diperoleh dari peristiwa tutur, $A$ (act sequences) yang mengacu pada bentuk dan isi tuturan dalam peristiwa tutur; $K$ (key) yang mengacu pada pesan, semangat yang dapat ditangkap dari ungkapan bahasa yang dituturkan termasuk pula perilaku nonverbal; I (instrumentalities) yang mengacu pada bentuk bahasa yang digunakan, $N$ (norm of interaction and interpretation) mengacu pada norma yang berlaku, dan $G$ (genre) yang mengacu pada bentuk penyampaian secara verbal (Wardhaugh, 1986:238-240).

1. Analisis Peristiwa Tutur dalam Prosesi Adat Pernikahan Gorontalo berdasarkan konsep SPEAKING 
Berikut ini hasil analisis peristiwa tutur dalam ketiga tahap prosesi adat pernikahan etnik Gorontalo yang dijabarkan sesuai dengan konsep SPEAKING oleh Hymes:

\section{a. Setting and Scene}

Motolobalango (meminang) merupakan salah satu dari tiga tahap terpenting dalam prosesi upacara adat pernikahan Gorontalo. Dalam hal ini, pihak keluarga laki-laki datang menemui pihak keluarga perempuan untuk meminang. Rumah kediaman orang tua calon pengantin perempuan (CPP) menjadi latar tempat untuk prosesi adat ini, sedangkan latar waktunya adalah sore hari setelah waktu salat asar atau dapat pula dilaksanakan pada malam hari. Situasi yang tergambar dalam tahap acara ini adalah situasi formal, tetapi tetap bernuansa kekeluargaan. Sementara itu, prosesi adat Modutu dilaksanakan sesudah prosesi Motolobalango yang pada zaman sekarang umumnya telah dilaksanakan pada hari yang sama dengan prosesi Motolobalango. Namun, ada pula sebagian orang yang melaksanakannya pada pagi hari menjelang akad nikah.

Prosesi adat Moponika terbagi atas dua bagian acara, yaitu mopotilandahu dan mongakaji. Acara mopotilandahu dilaksanakan di rumah orang tua CPP dan latar waktu pelaksanaannya malam hari, sehari sebelum acara mongakaji. Nuanasa religiusnya sangat kental karena pada malam tersebut CPP akan melantunkan ayat-ayat suci Alquran dalam proses khatam Alquran. Selanjutnya, suasana akan berubah ceria ketika calon pengantin laki-laki (CPL) akan menari "saronde" (molapi Saronde) dan CPP menari "tidi" (motidi). Sementara itu, acara mongakaji (mengakad) dilaksanakan pula di rumah orang tua CPP dan wajib dilakukan di dalam rumah, tepatnya dalam induk rumah, bukan di teras rumah atau di pelaminan. Waktu pelaksanaannya lazim dilakukan pada pagi hari.

\section{b. Participants and Prop}

Peserta yang hadir dalam prosesi adat motolobalango terdiri dari pemangku adat yang berjumlah enam orang dan bertugas menyiapkan dan memimpin penyelenggaraan upacara adat dari awal hingga akhir; keluarga dekat kedua calon pengantin yang akan menjadi saksi keluarga mewakili orang tua; kadhi (imam) dan wakilnya yang bertugas memimpin upacara pernikahan secara syariat Islam; dan pihak pemerintah (taa tombuluwo) sebagai pihak yang diundang untuk memberi restu pelaksanaan upacara adat ini. Sementara itu, atribut adat yang digunakan dalam prosesi adat ini terdiri dari perlengkapan adat yang dibagi atas tiga bagian yaitu, tapabula bu'olo ngango yang berisi tonggu (alat pembayaran adat) yang diletakkan di atas baki beralaskan lenso krawang warna adat (merah, kuning, hijau, ungu) dan dipayungi dengan toyungo bilalalngo (payung kebesaran adat), mama ngotapabula berisi pomama (tempat sirih pinang lengkap dengan isinya), tapahula mama lo'ongongalaa yang berisi sirih pinang, gambir, tembakau dalam jumlah yang banyak.

Sementara itu, dalam prosesi modutu, partisipan yang hadir terdiri dari pemangku adat yang berjumlah enam orang, keluarga dekat yang mewakili orang tua kedua calon pengantin, kadbi dan wakilnya, pemerintah setempat, pembawa antaran harta adat (sakili), dan calon pengantin perempuan (CPP). Atribut adat yang menjadi unsur penunjang utama dalam prosesi adat ini terdiri dari tapahula berisi tonelo (mahar), tapabula berisi alat pembayaran adat yang terdiri dari tonggu (uang adat), kati, tutu lo polidulu (pembayaran untuk juru rias), buluwa lo umonu (peti wangi-wangian), bunggato (pembayaran adat untuk pemangku adat dan 
imam), luwalo, beyi lo buheputo, dudelo, wulo lo oato sasuku (pencuci kaki), tilolo sayelali; satu baki berisi peralatan kosmetik dan peralatan mandi; sirih, pinang, gambir, dan tembakau diletakkan dalam empat baki, dan payung adat. Selain itu, terdapat pula ayua yang berisi lima macam buah, yaitu limu (jeruk kelapa), nanati (nenas), langge (nangka), patodu (tebu), dan bongo tumula (kelapa bertunas). Atribut adat lain berupa kola-kola atau usungan berbentuk perahu yang terbuat dari bambu kuning berhias janur dan diletakkan dalam kendaraan. Kola-kola itu mengangkut beras, rempah-rempah, dan hewan, contohnya sapi, kambing, atau ayam.

Pada prosesi adat moponika, partisipan yang hadir terdiri dari pemangku adat kedua belah pihak keluarga yang bertugas mengatur pelaksanaan secara adat sejak awal hingga akhir, imam yang memimpin doa khatam Alquran, calon pengantin laki-laki, calon pengantin perempuan, orang tua kedua calon pengantin, seorang ibu yang mendampingi calon pengantin perempuan ketika mengkhatam Alquran, dan keluarga serta teman-teman kedua calon pengantin. Padaprosesiadat mongakaji, partisipan yang hadir adalah partisipan yang hadir pada tahap mopotilanndabu ditambah dengan petugas pencatat nikah yang akan mencatat pernikahan tersebut. Sementara itu, atribut adat yang dihadirkan, antara lain Alquran, alikusu (gapura adat), tolitihu (tangga adat), puade, perlengkapan tari saronde dan tidi, pakaian, dan genderang adat (bantalo).

\section{c. Ends}

Prosesi adat motobalango bertujuan menghubungkan ikatan silahturahmi keluarga kedua calon pengantin. Prosesi ini mengandung makna sebuah permintaan secara resmi dari pihak laki-laki kepada pihak perempuan untuk menjadi istrinya sehingga hal utama yang menjadi inti pembicaraan dalam prosesi ini adalah penegasan hasil pembicaraan kedua orang tua calon pengantin pada tahap sebelumnya atau dengan kata lain untuk merealisasikan hasil musyawarah informal keluarga (dulobupa) sebelumnya. Sementara itu, prosesi modutu dilaksanakan untuk memenuhi syarat-syarat yang diminta pihak keluarga calon pengantin perempuan dalam melaksanakan pernikahan, baik secara syariat Islam maupun secara adat Gorontalo. Selain itu, prosesi modutu menjadi wadah pemberitahuan secara resmi kepada kaum keluarga kedua belah pihak bahwa dalam waktu dekat akan ada pernikahan yang tanggal pelaksanaanya akan dibicarakan dalam prosesi modutu ini. Prosesi adat moponika terdiri dari acara mopotilandahu dan acara mongakaji. Acara mopotilandabu bertujuan untuk menanamkan prinsip religius dalam diri pengantin perempuan dan meyakinkan kepada pihak keluarga laki-laki bahwa pengantin perempuan adalah seorang gadis yang taat beragama. Sementara itu, acara mongakaji bertujuan untuk mengesahkan secara resmi hubungan seorang laki-laki dan seorang perempuan dalam tali pernikahan, baik secara syariat Islam maupun menurut keluhuran adatisiadat.

\section{d. Sequences}

Bentuk wicara yang tampak dalam prosesi motolobalango, yaitu wacana verbal dan nonverbal dengan media komunikasi tuturan lisan dari juru bicara keluarga pengantin laki-laki kepada juru bicara keluarga pengantin perempuan. Dalam prosesi motolobalango pada akhir prosesi peminangan, wacana nonverbal tampak dari perilaku kedua juru bicara yang berdiri berhadapan dan dibatasi dengan kain alas, lalu duduk dengan posisi duduk di atas lipatan kaki 
kiri, sedangkan kaki kanan tegak, kemudian mereka berjabat tangan seraya melantunkan tuja'i bergantian: "depita mayilapato, salawati upo'o patato, amanati pilo dudulo, waw delo bungo sambako, maa longoalo to wombato ito waw watotiya, humaya delo butiya, buta'o didu motiiya" (segala sesuatu telah selesai,jabatan tangan memperjelas, amanatyang disampaikan laksana sekuntum bunga cempaka, mekar di atas alas, Anda dan saya laksana rotan dibelah tak akan terpisah). Sementara dalam prosesi modutu, wacana verbal tampak dalam ungkapan-ungkapan yang mengambarkan penegasan sikap kedua pihak keluarga mengenai harta pernikahan, sedangkan wacana nonverbal tampak dalam perilaku partisipan terutama juru bicaranya, termasuk pula kepercayaan etnik Gorontalo dalam menyikapi hal-hal yang berkaitan dengan harta pernikahan, yaitu bahwa mereka tidak mengenal ungkapan 'momate tulu' (memadamkan api) yang bermakna semua urusan harta seluruhnya dari pihak laki-laki. Sebaliknya, mereka meyakini ungkapan 'mobaliya atau motunggala' yang mengandung makna semua urusan ditanggung secara bersamasama. Selanjutnya, dalam prosesi moponika, wacana verbal tampak dalam tuja'i dan palebohu yang dilantunkan baate. Wacana nonverbalnya tampak dalam perilaku partisipannya, seperti: juru bicara keluarga yang berdiri di hadapan Taa Tombuluwo sembari memberi penghormatan adat (molubo), pengantin laki-laki dan orang tua/wali pengantin perempuan berjabat tangan sambil ujung ibu jari masing-masing saling menyentuh ketika dilakukan akad nikah.

\section{e. Key}

Dalam prosesi motolobalango juru bicara keluarga bersikap serius dalam berbicara dengan nada suara merendah ketika melantunkan tuja'i yang berisi ungkapan bermakna permohonan.
Hal ini bertujuan untuk menghindari terjadi kesalahpahaman antara kedua pihak keluarga. Sementara pada prosesi modutu, kedua juru bicara keluarga berbicara dengan nada agak tegas dan serius begitu pula halnya dengan partisipan yang serius mendengarkan tuja'i-tuja'i dari kedua juru bicara keluarga, sedangkan pada prosesi moponika, tuja'i dilantunkan dengan nada gembira, tetapi dengan kata-kata santun.

\section{f. Instrumentalities}

Dalam ketiga prosesi adat pernikahan, juru bicara keluarga laki-laki menyampaikan maksud kedatangan mereka secara lisan dalam bahasa Gorontalo, begitu sebaliknya dengan juru bicara keluarga perempuan.

\section{g. Norm of Interaction and Interpretation}

Tahapan prosesi motolobalango dan modutu bersifat formal sehingga partisipan yang hadir pun berusaha menjaga kekhidmatan acara ini. Tahap demi tahap acara ini dilaksanakan sesuai dengan aturan adat yang berlaku dan tidak boleh ada yang terlewatkan. Sementara itu, pada prosesi moponika, tahap acara mopotilandahu bersifat nonformal, tetapi partisipan tetap harus mematuhi norma-norma yang berlaku di dalamnya, misalnya pengantin laki-laki tidak boleh melangkah masuk ke dalam rumah sebelum dituja'i mopotunoto; pengantin perempuan harus duduk di dalam kamar pengantin sebelum dijemput baate untuk acara mohatamu dan motidi.

\section{h. Genre}

Pada ketiga prosesi adat motolobalango, modutu, dan moponika gaya penyampaian ungkapan bahasa oleh juru bicara pengantin laki-laki dan juru bicara pengantin perempuan direalisasikan dalam bentuk pernyataan biasa, peribahasa, maupun perumpamaan yang dituja' $i$-kan. 
2. Makna Budaya Ungkapan dalam Prosesi Adat Pernikahan Gorontalo a. Ungkapan dalam Prosesi Adat Motolobalango:

Albamdulillab
Amiyatiya malo'otodwwo dalalo
Amiyatiya momaapu
Bolo woluwo wbilapu
Bolo dongso amijativa talayilayadu
Tala lumadu
Bo donggo odito
Payu lo dulwwo mobutato
Wanu dila bumayapo
Dila mo'otoduwo baato

Makna budaya yang terkandung di dalam ungkapan ini adalah pola adat-istadat Limutu Hulonthalo sudah mengatur agar sebagai orang Gorontalo selalu menjaga pola kesantunan dalam perilaku, baik lisan maupun tulis.

\section{Alhamdulillab \\ Debo woluwo ongongala taa dipoluzo \\ Bo bumaya odelo tuladu \\ Demaa tomatangalo bua-buadu \\ Wonu bumaya odelo kitabi \\ Demaa tomatangalo ngadi-ngadi}

Makna budaya yang terkandung dalam ungkapan ini adalah ikatan kekeluargaan yang sangat kental dalam masyarakat etnik Gorontalo, terbukti dari harapan pengantin agar keluarga hadir dalam pernikahannya. Hal ini tidak terlepas dari salah satu hakikat pernikahan yang menganggap bahwa pernikahan bukan hanya menjadiurusankeduacalonpengantin,melainkan sudah menjadi urusan keluarga sehingga harus

Paramata to buwali

Unti-unti to lamani

Wonulijo kakali

Wanu bolo dipole taalu babari

Paramata sinibuwa

Wonu to tabuwa

Unt-unti to buluwa

Wonu tootutwiva

Bolo dipolu bi yinggu-yingrwa segala puji bagi Allah

kami sudah mendapat jalan

kami mohon maaf

apabila ada yang khilaf

bila kami sempat bertanya

atau mengumpamakan

karena seperti itulah

pola persaudaraan dua negeri ini

apabila tidak menggunakan perumpamaan idak memberi kenyataan

Contohnya, ketika menyampaikan suatu hajat, orang Gorontalo akan menggunakan ungkapanungkapan, baik dalam bentuk peribahasa maupun perumpamaan yang di-tuja'i(dipuisikan) untuk menghindari kesalahpahaman.

Segala puji bagi Allah

masih ada keluarga yang belum datang

namun laksana sepucuk surat

nanti dibaca dulu

bila diibaratkan Alquran

biarlah nanti dibaca dalam pengajian

dimusyawarahkan dan diputuskan dalam keluarga, seperti tampak dalam ungkapan yang sudah terpatri dalam budaya Gorontalo berikut ini: donggo to delomo ombongo wala'o to dulota, dabo to'u maa yilumualai ode dunia, tio malowali weala'o ta daadaata (ketika masih dalam kandungan anak milik kami berdua, tetapi setelah lahir anak ini milik keluarga).

permata di dalam kamar

terkunci di lemari

harum sepanjang masa

belum adakah yang mengirim kabar

permata gemilang

harum semerbak dalam peraduan

terkunci dalam peti besi

harum benar

kiranya belum ada yang mengenangkan 
Paramata to buwali

Unti-unti to lamani

Wonuljo kakali

Wanu bolo dipole taalu babari

Paramata siribuwa

Wоми to tabuva

Unt-unti to buluwa

Wonu tootutuwa

Bolo dipolu bi yinggu-yingguwa permata di dalam kamar

terkunci di lemari

harum sepanjang mas a

belum adakah yang mengirim kabar

permata gemilang

harum semerbak dalam peraduan

terkunci dalam peti besi

harum benar

kiranya belum ada yang mengenangkan

Makna budaya yang tersirat dalam ungkapan kecantikan gadisnya dengan menggambarkan peminangan di atas menunjukkan kesungguhan kecantikan si gadis seperti emas dan intan calon pengantin laki-laki yang menyanjung permata.

Alhamdulillah

Putungo bungo kanari

Longo'alo to buali, moonu kaka-kakali

Intani paramata

Wonu-wonu to bubalata

Boli unti-unti to buluwa

Dipolu taa lo minggolo

Boheli ito-itolo

Wanu tubata bahasa

Loiya moopalata

Wanu tuhata loiya

Du'awo mo'owaliya segala puji bagi Allah

kuncup bunga kenari

mekar di kamar, semerbak harum baunya

intan permata

harum semerbak dalam peraduan

yang terkunci dalam peti besi

belum ada yang mengikat

barulah Anda sendiri

bila tepat tata bahasa

yang dimaksud akan tercapai

bila tepat tutur kata

doakan seia sekata

Makna budaya ungkapan dalam trija'i di atas

Hal ini sesuai dengan ketentuan adat etnik mengisyaratkan bahwa gadis yang ingin dilamar oleh keluarga laki-laki adalah gadis yang masih terjaga kesuciannya yang diibaratkan seperti Gorontalo yang menetapkan bahwa hanya gadis yang masih suci yang boleh menjalani prosesi adat dalam pernikahan.

intan permata yang terkunci dalam peti besi.

\section{Mama ngotapabula \\ Modaha u olumbula \\ Wali li matodula \\ Wombu li tolangobula}

\section{Lintonga pobotulalo}

Haya'a waw tanggalo

Potala diila malo odelo haya'o dalalo

Toowoluwo lo bunting waudilito

Potala diila malo odelo ayopa lo yilito

Owoluwo lo buntingo waw turdu

Potala diila malo odelo langgato buidu

Dalam ungkapan yang terangkum dalam tuja' $i$ di atas tersirat pentingnya arti sirih pinang (mama pilitango) dalam kehidupan masyarakat Gorontalo. Dalam budaya Gorontalo, sirih sirih pinang dalam peti adat

penjaga agar tidak terhalang

asal keturunan bangsawan sejati cucu leluhur yang berbudi

palang adat

panjang dan lebarnya

moga-moga tidak sepanjang jalan

ketentuan dari pola adat

moga-moga tidak sedalam jurang

ukuran dan takaran

moga-moga tidak setinggi gunung

pinangyangdipercayabermanfaatbagikesehatan gigi banyak dikonsumsi dengan cara dikunyah, terutama oleh orang tua. Pemberian sirih pinang mengandung makna untuk melancarkan 
pembicaraaan/musyawarah selanjutnya antara kedua keluarga, terutama mengenai mahar yang akan diberikan kepada calon pengantin perempuan, seperti tampak dalam ungkapan
Payu lo Limutu-Hulontalo

Maa tayo-tayolo dalalo

Dalalo maapidu-piduduto

Waw didu moluluto

Ayitilo to bobuliyo

Tunggulo pulitiyo

Didu boli tabuyi sisaliyo

Adati liyombuto mulo

Dabayi bolo lumumbulo

Wapi to pilomulo

Maapunga moopulo

Ode tawn mo lopulo mama ngotapabula, modaha u olumbula'sirih pinang dalam peti adat, penjaga agar tidak terhalang'. Harta mahar dalam tuja'i dikiaskan sebagai lintonga pobotulalo 'palang adat'.

Ungkapan di atas menyiratkan bahwa menggunakan kata 'dalalo' yang menyiratkan dalam pola adat Gorontalo-Limboto sudah makna ketentuan adat. Etnik Gorontalo wajib ada ketentuan baku yang mengatur syarat mematuhi ketentuan adat tersebut jika tidak kelengkapan adat yang harus dipenuhi ingin mendapat malapetaka seperti yang tersirat dalam suatu pernikahan. Ungkapan di atas dalam bait-balit tuja'i.

Depita mayilapato

Salawati upo'o patato

Amanati pilo dudulo

Waw delo bungo sambako

Maa longoalo to wombato

Ito waw watotiya

Humaya delo butiya

Buta'o didu motiya

Watotiya waw ito'

Odelo tola ngobotu layito

Made pilutu lopito

Lalango de molonito

Tonulalo uyululito

Diila pomukiri ito pola adat Limboto-Gorontalo

sudah ada jalan

jalan sudah tersusun rapi

dan tidak terhapus

tuturkan pada awalnya

tuturkan pada awalnya

jangan sampai ada tersisa

adat istiadat leluhur kita

jaga jangan sampai punah

tanaman pun akan diserang

akan dilaknat dan mendapat musibah

manusia akan binasa
Makna budaya yang tersirat dalam ungkapan berbentuk tuja'i pada bait pertama adalah halhal yang sudah disepakati dalam musyawarah keluarga tetap dipegang teguh oleh kedua keluarga. Selain itu, silaturahmi keluarga tetap menyatu tak terpisahkan seperti dalam ungkapan bumaya delo butiya, buta'o didu motiya laksana rotan, dibelah tak akan terpisah'. Penggunaan simbol flora dan fauna sangat tampak dalam semua telah selesai

jabatan tangan memperjelas

amanat yang disampaikan

laksana sekuntum bunga cempaka mekar di atas alas

Anda dan saya

laksana rotan

tak akan terpisah

saya dan Saudara

laksana seekor ikan gabus yang utuh

dipotong dengan pisau

dibakar berbau sedap

apa yang telah diungkapkan

insya Allah tidak dipungkiri

ungkapan tersebut, seperti bunga sambako 'bunga cempaka' dalam ungkapan waw delo bungo sambako, maa longoalo to wumbato 'laksana sekuntum bunga cempaka, mekar di atas alas'. Ungkapan ini mengandung makna kiasan yang menggambarkan pihak keluarga laki-laki menyepakati persyaratan harta pernikahan yang diminta dan bersedia memenuhinya. 


\section{b. Ungkapan dalam Prosesi Adat Modutu}

\section{Adati lo bunggiya \\ Maatilumapalayi odiya \\ Wanu bolo maaluasiya \\ Maalayio mayide yiladiya \\ Adati liyombuto \\ Toduwolo mobotulo \\ Wombuto maasadiya \\ Bubato maabibadiriya}

adat negeri

kini sudah sampai

kalau sudah diperluas

akan naik ke rumah

adat leluhur kita

silakan dinaikkan

tikar sudah tersedia

pembesar negeri telah hadir

Makna budaya yang terkandung dalam semua perlengkapan adat antaran pernikahan, ungkapan di atas menyiratkan sikap orang walaupun saat ini sudah banyak tersedia karpet Gorontalo yang tetap mempertahankan ciri beraneka warna dan corak. Anyaman tikar khas budayanya dengan tetap menggunakan ini terbuat dari sejenis tumbuhan yang hanya wombato (tikar) sebagai alas tempat menggelar tumbuh di daerah pinggiran Danau Limboto.

Bismillah molomulo
Aadati lo'umulo
Oyintaliyo tonggu
Tonggu lo wunggumo
Lopotuwawn dulungo
Oluwoliyo kati
Kati lo adati
Lodingo waw sarati
Lowali pake-pakeati olanto jamaati
Otoluliyo maharu
Totapalu molamahu
Tunubiyo minya wangi
O cipu waw Quru'ani
Waw bualimo o barliani
Opatiyo tapabula
Tuwoto umaloponuwa
Tunuiyo hungo lo aywwa
Mulo-mulo de tawwa
Tunubiyo lubuto
Tuwoto umaaletibuto
Tunubiyo gambele
Tuwoto umaamayi motomele
Tunubiyo tembe
Modaha umaamayi motilengge
Tunubiyo taba'a
Modaha umaamayi motambaa

Bismillah molomulo

Oluwoliyo kati

Kati lo adati

Lowali pake-pakeati olanto jamaati

Otoluliyo mabaru

Totapalu molamahu

Tunubiyo minya wangi

O cipu waw Quru'ani

Waw bualimo o barliani

Opatiyo tapabula

Tuwoto umaloponuwa

Tunuiyo bungo lo ayuwa

Mulo-mulo de tauwa

Tunubiyo lubuto

Tunoto umaaletibuto

Tunubiyo gambele

Tuwoto umaamayi motomele

Tunubiyo tembe

Tunubiyo taba'a

Makna yang tersirat dalam tuja'i di atas selain materi adat antaran yang harus dipenuhi sesuai dengan ketentuan adat, tata cara penyerahannya harus secara berurutan dari tonggu hingga tembakau dan mendahulukan pihak pemerintah dengan nama Allah sebagai awal mula adat dari leluhur kita yang pertama tonggu adat pembuka bagi yang diam telah menyatukan tujuan yang kedua kati

martabat dalam adat jadi takaran dan persyaratan menjadi pakaian bagi kita semua ketiga mahar pada wadah yang indah disertai minyak wangi ada cipu dan Alquran dan cincin berlian keempat peti adat

pertanda seia sekata dilengkapi dengan buah-buahan

dahulukan pembesar negeri disertai pinang

pertanda sudah terikat disertai gambir pertanda menjadi serumah disertai sirih mencegah untuk angkuh disertai tembakau mencegah silang sengketa menerima buah-buahan. Hal ini mengandung makna bahwa kedua calon pengantin dalam menjalani bahtera rumah tangga harus memiliki sifat disiplin, saling menghargai dan hormatmenghormati. 


\title{
c. Ungkapan dalam Tuja'i dalam Prosesi Adat Moponika
}

1) tuja'i mopolahee taeya:

Pangge wahu pangge

Pangge u oduta'a

Pangge u otibula

Wombu li tolangobula

Wali li matoladula

\author{
berhati-hatilah \\ berhati-hatilah pada tanah yang dipijak \\ berhati-hati pada tempat berdiri \\ cucu tolangobula \\ turunan raja matoladula
}

Makna budaya yang tersirat dalam tuja'i ini katanya berpegang teguh pada ajaran agama dan adalah kedua pengantin harus selalu menjaga aturan adat yang sesuai dengan syariat Islam.

perilakunya, baik dalam tindakan maupun tutur

tuja'i mopotupalo:

Wombu tupalolomai

Tupalai to dutula

Talubu waw buluwa

Maalo liiyatuwa

Ode tumula popalo

Lotutai lopopalo

Ode timo ipitolo

Ode pini bubo'alo

Ode bulawa putalo cucu disilakan masuk

masuklah melalui jalur ini air dan peti

membaur jadi satu

bagai bambu pecah siap dianyam

dilicinkan dan diluruskan

bagai timah ketemu tuangan

laksana kapas yang putih bersih

laksana emas murni

Kata dutula dalam bahasa Gorontalo ungkapan dalam tuja'i ini mengandung makna mengandung makna leksikal 'sungai', tetapi dalam menjalankan bahtera rumah tangga, dalam tuja'i ini mengandung makna 'jalur' atau kedua pengantin harus selalu menyatukan ‘jalan' yang akan dilewati pengantin. Makna jalur atau jalan dianalogikan dengan air sungai yang mengalir secara teratur. Secara keseluruhan, pendapat, saling menyayangi, seiring sejalan, seia sekata, memiliki hati yang bersih, dan sifat 2). Tuja'i mopondalengo:

Dahayi umaayango

Ode botu to payango

Dahayi ulumodu'o

To baleyango bituo bituiyo tajeuwa

Tomadala lo labuwa

Olongia tombuluwa

Wuudu olongia

Tombuluwa tadidiya rendah diri dalam kehidupan sehari-hari.

Ungkapan dalam tuja'i ini mengandung makna agar pengantin mempunyai pendirian yang teguh dan tidak mudah tergoda oleh godaan apa pun kalau ingin menjaga keutuhan

jaga jangan sampai beralih laksana batu dalam peraduan jaga jangan sampai tenggelam pada gelombang ketajaman alur pikir pada seluruh penjuru negeri pimpinan yang dihormati ketentuan bagai pemimpin dijinjing dan dihormati

rumah tangganya. Selain itu, dalam kehidupan bermasyarakat, pengantin harus memiliki sifat saling menghargai, hormat-menghormati, terutama kepada pemimpinnya.
3).Tuja'i mopobotulo:

Wombu pulu lo labua

Lo lipu pilobumbuwa

Li bapu waw liuwa

Tobuliya tota'uwa

Hidapata biwuluwa

Tombuluwo wunduwolo cucunda putra negeri

dari negeri tempat asal

para kakek dan leluhur

di hilir maupun di hulu

telah siap dengan tertib

pembesar negeri menyanjung 
Wahu maa pobutuwolo

Lopohuli lo umololo dan akan melaksanakan

tata upacara para pendahulu
Menurut ketentuan adat etnik Gorontalo, khususnya dalam pernikahan adat, rumah pengantin wanita tetap harus dibuatkan tangga adat (tolitibu), walaupun bentuk rumahnya sudah memiliki tangga. Ungkapan di atas mengandung makna budaya bahwa kedua pengantin pada 4) Tuja'i mopodiambango

Malo payu lo bumolu

Lipu duluwo tilolu

Obutu ololu

Payu lo lipu duluwo

Didu boli lilawuwo

Mo'ohuli moobuyo

Iyaiyati lo lumo

Odelobulango lowningo

Hililaya hilinggimo

Ami wombu liyombu laingo

Makna budaya dalam ungkapan ini menyiratkan agar kedua pengantin harus berhati-hati membawa diri dalam pergaulan. Mereka akan dipersatukan secara agama dan adat yang sangat dijunjung tinggi. Oleh karena itu, mereka harus bisa mengamalkan dalam kehidupannya sehari-hari, apabila tidak ingin celaka atau diasingkan sehingga tidak ada penyesalan di kemudian hari.

\section{Pola Pikir Masyarakat Etnik Gorontalo dalam Tuja'i dan Palebobu}

Menurut Spradley (1979), pola pikir masyarakat berkaitan dengan tema budaya dari suatu komunitas budaya etnik tertentu. Tema budaya sendiri dimaknai sebagai suatu prinsip kognitif yang bersifat tersirat maupun tersurat dan berulang dalam sejumlah domain dan berperan menghubungkan berbagai subsistem makna budaya. Budaya adalah pola pikir yang merupakan sistem kognisi yang dikeluarkan melalui bahasa, baik dalam bentuk lisan maupun bahasa tulis. Oleh karena itu, untuk dapat hari pernikahannya dimuliakan secara adat selayaknya raja dan ratu sehari. Makna lain adalah kedua pengantin harus memegang prinsip kehati-hatian dalam menjalankan biduk rumah tangganya.

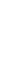


Oleh sebab itu, segala urusan yang berkaitan dengan pernikahan selalu diputuskan dalam musyawarah keluarga dan acara akad nikahnya selalu dihadiri oleh seluruh anggota keluarga, baik dari segi kedekatan hubungan kekeluargaan maupun dari segi letak tempat tinggalnya dari lokasi pernikahan. Acara pernikahan bagi etnik Gorontalo menjadi media pelepas rindu bagi anggota keluarga yang jarang bertemu dan menjadi media perkenalan anggota keluarga/ anak cucu yang belum saling mengenal.

Aspek kekerabatan tersirat dalam ungkapan yang disampaikan ayah calon pengantin wanita ketika menerima kunjungan awal orang tua calon pengantin pria pada tahap molenilo: "amiyatiya mobile ma'apu, wonи maali amiyatiya donggo mo'otaawapo wolo ongo ngaala'a sababu donggo to delomo ombango wala'o ta duulota, dabo to'u maa yilumualai ode dunia, tiyo maloali wala'o to dadaata" (kami minta maaf kalau boleh kami bermusyawarah terlebih dahulu dengan seluruh keluarga, sebab ketika masih dalam kandungan, anak ini milik kami berdua, tetapi setelah lahir anak ini milik keluarga). Ungkapan lain yang menyiratkan aspek kekerabatan dalam etnik Gorontalo, yaitu: 1) "U mulo-mulo yilawadu lamiyatiya, bolo woluwo ongongala'a pilo layiliya, waw dipolu hihadiliya,ongongala'a pilo layiliya, waw dipolu bihadiliya, ongongala'a tiloduwo waw dipoluwo, ongongala'a bolitula'a'o to tu'adu, meyambola yilawola maa tuladu" (yang pertama-tama kami tanyakan adakah keluarga yang diharapkan dan belum hadir di tempat ini, keluarga yang diundang dan belum datang, keluarga yang didatangi atau dikirimi surat dan belum bersama kita?) 2) alhamdulillah debo woluwo ongongala" a taa dipoluwo bo bumaya odelo tuladu, demaa tomatangalo buabuadu, wonu bumaya odelo kitabi, demaa tomatangalo ngadi-ngadi (segala puji bagi Allah, masih ada keluarga yang belum datang, tetapi laksana sepucuk surat, nanti dibaca dulu, bila diibaratkan Alquran biarlah nanti dibaca dalam pengajian). Aspek ikatan kekerabatan yang kuat dalam etnik Gorontalo jelas tersirat dalam ungkapanungkapan di atas yang selalu melibatkan keluarga dalam masalah yang berkaitan dengan pernikahan.

\section{b. Hubungan Sosial}

Pernikahan merupakan salah satu cara untuk menjalin hubungan kekerabatan baru antara keluarga laki-laki dan keluarga perempuan. Selain itu, dalam kehidupan sosialnya etnik Gorontalo sangat mengagungkan nilai-nilai tata krama dalam pergaulan. Hal ini dilandasi oleh kepatuhan orang Gorontalo terhadap norma adat yang bertopang pada syariat Islam. Budaya tata krama dalam pergaulan sudah mengkristal dalam kehidupan etnik Gorontalo yang diwariskan secara turun temurun. Contohnya adalah tata krama dalam menghormati orang tua dan yang dituakan, bersalaman, makanminum, berbicara, dan bertegur sapa. Selain itu, penggunaan ungkapan-ungkapan tidak langsung dalam bentuk peribahasa ataupun perumpamaan merupakan gambaran karakter etnik Gorontalo yang selalu menjaga pola kesantunan dalam berbicara demi menghindari kesalahpahaman.

Aspek hubungan sosial pun dapat dilihat pada pola perilaku etnik Gorontalo yang sangat menghormati pemimpinnya. Tabuda (pesan kearifan) yang ditinggalkan oleh Sultan Eyato, yaitu adati bula-bula'o to sareati, sareati bula-bula'o to Kitabullah 'adat bersendikan syarak, syarak bersendikan kitabullah' menjadi bukti sifat orang Gorontalo yang religius. Ketaatan pada adat-istiadat berlandaskan agama tampak dalam tuja'i dan palebobu yang dilantunkan dalam 
rangkaian upacara adat pernikahan.

Sifat musyawarah untuk mufakat (dulohupa) juga menjadi salah satu ciri karakter etnik Gorontalo seperti tampak dalam ungkapan berikut:"amiyatiya tawubotulo dila lumbaa lumbolo, donggo modata u olipata, bolo mo harapu potuhata, alibu itu mowali basarata, buidu mowali data" (kami datang bertamu mohon tidak dipandang mengganggu, masih banyak hal yang terlupakan, tinggal mengharapkan petunjuk, supaya kita jadi terpadu, gunung pun menjadi dataran).

\section{c. Aspek Material}

Aspek material mencakup penggunaan unsurunsur alam di dunia ini sebagai bukti karakter etnik Gorontalo yang selalu bersyukur atas semua rahmat Tuhan YME. Sumber alam yang sering digunakan sebagai atribut adat oleh etnik Gorontalo, misalnya sirih, pinang, dan kelapa bertunas. Empat unsur alam utama, yaitu buta (tanah), talubu (air), doputo (angin), dan tulu (api) mengilhami filosofi kehidupan etnik Gorontalo. Ada empat unsur alam yang menjadi referen bagi jumlah atribut adat yang digunakan dalam prosesi adat antaran harta (modutu), yaitu sirih, pinang, gambir, tembakau. Empat simbol adat ini wajib ada dalam prosesi antaran harta.

\section{Simpulan}

Berdasarkan pembahasan yang telah diuraikan di atas, maka disimpulkan sebagai berikut:

1. Ungkapan-ungkapan yang terdapat dalam peristiwa tutur pada ketiga tahap prosesi adat pernikahan Gorontalo ini berbentuk peribahasa, perumpamaan yang dilantunkan dalam bentuk tuja'i dan palebohu. Tuja'i adalah bentuk puisi adat yang dilantunkan dalam ketiga tahap acara yang mengandung makna permohonan ataupun penegasan tentang sesuatu hal, sedangkan palebohu adalah puisi adat yang hanya dilantunkan dalam prosesi moponika ketika kedua pengantin sudah duduk di pelaminan. Palebohu berisi nasihat kepada pengantin dalam menjalankan bahtera rumah tangganya. Ungkapan-ungkapan tersebut menggunakan bahasa yang santun sehingga maksud dan pemikiran yang terkandung di dalamnya dapat diterima dengan baik oleh kedua pihak keluarga.

2. Makna budaya yang tersirat dalam ungkapanungkapan pada peristiwa tutur, baik secara verbal maupun nonverbal dihasilkan dari korelasi makna ungkapan tersebut yang dihubungkan dengan konteks budaya Gorontalo.

3. Pola pikir masyarakat etnik Gorontalo yang terkandung dalam ungkapan-ungkapan bernilai positif menggambarkan karakter etnik Gorontalo yang bersifat religious, mengagungkan nilai-nilai tata krama dalam pergaulan, kekeluargaan, pekerja keras, menghormati pemimpinnya, dan mementingkan musyawarah untuk mufakat. 


\section{Daftar Pustaka}

Badudu, J.S. 1982. Morfologi Babasa Gorontalo. Jakarta: Djambatan.

Botutihe, M.Hi. dan F. Daulima. 2003. Tata upacara Adat Gorontalo. Gorontalo: Pemerintah Daerah Gorontalo.

Botutihe, M.Hi. 2003. Gorontalo Serambi Madinab: Obsesi dan Perubahan Menuju Masyarakat yang Sejabtera dan Berkualitas. Jakarta: PT Media Otda.

Breukink, J.1906. Bijdragen Tot Eene Gorontalosche Spraakkunst. S'Gravenhage: Martinus Nijhoff.

Casson, R.W. 1981. Language, Culture, and Cognition: Anthtopological Perspectives. New York: Macmillan Publishing Co. Inc.

Folley, A.W. 1997. Anthropological Linguistics: An Introduction. Oxford. England: Blackwell Publishers Ltd.

Hymes, D. 1974. "Linguistics Method in Ethnography: Its Development in the United States" dalam Method and Theory in Linguistics. Paul Garvin, Mouton, Hogue (Eds).

Kadarisman, A.E. 2005. "Relativitas Bahasa dan Relativitas Budaya." Linguistik Indonesia. Agustus 2005. Jurnal Ilmiah Masyarakat Linguistik Indonesia. Jakarta, Agustus 2005. ISSN:0251-4846.
Koentjaraningrat. 1985. Beberapa Pokok Antropologi Sosial. Jakarta: Dian Rakyat.

Kridalaksana, H. 1984. Kamus Linguistik. Jakarta: PT. Gramedia.

Lihawa, K. 2008. Materi Kongres Internasional Bahasa dan Adat Gorontalo I. Goronalo: Universitas Negeri Gorontalo.

Marnita dan Oktavinaus. 2008. "Perilaku Berbahasa Masyarakat Minangkabau dan Pengaruhnya terhadap Pemakaian Ungkapan sebagai Media Pendidikan Informal Keluarga." Linguistik Indonesia. Jurnal Ilmiah Masyarakat Linguistik Indonesia, Jakarta. Nomor 2 tahun ke-26. ISSN: 0215-4846. Hal. 219-231

Pateda, M. 1977. Kamus Bahasa GorontaloIndonesia. Jakarta: Pusat Pembinaan dan Pengembangan Bahasa, Departemen Pendidikan dan Kebudayaan.

Usman D. K. 2008. Materi Konggres Internasional Bahasa dan Adat Gorontalo I. Gorontalo: Universitas Negeri Gorontalo.

Wardhaugh. R. 1986. An Introduction to Sociolinguistics. Oxford UK: Basil Blackwell Ltd. 